\title{
Prevalence of Asymptomatic Hiatal Hernia in Obese Patient in Routine Upper Gastrointestinal Endoscopy Screening and Correlation with BMI
}

\section{Bandar Saad Assakran}

King Fahad Specialist Hospital

Khaled Mohammed Alrakbi

King Fahad Specialist Hospital

Meshari Abdulrahman Alharbi ( $\triangle$ Mshary_7777@hotmail.com )

Qassim University https://orcid.org/0000-0002-5902-9428

\section{Moath Abdullah Almatroudi}

Qassim University

\section{Asim Nizar Alshowaiman}

Qassim University

\section{Abdullah Homood Alromaih}

King Fahad Specialist Hospital

\section{Basil Abdulrahman Alharbi}

Qassim University

Naif Suliman Alaqil

Qassim University

\section{Ali Saleh Alsoghayer}

Qassim University

\section{Research article}

Keywords: Hiatal hernia, obese patient, upper gastrointestinal endoscopy screening, BMI

Posted Date: October 24th, 2020

DOI: https://doi.org/10.21203/rs.3.rs-44052/v2

License: (1) (i) This work is licensed under a Creative Commons Attribution 4.0 International License. Read Full License 


\section{Abstract}

Background In obese patients, hiatus hernia $(\mathrm{HH})$ can be asymptomatic or it may present with one or few symptoms such as heartburn, nausea, or vomiting. Routine upper gastrointestinal endoscopy is the most frequent method to determine the presence of any abnormalities including hiatus hernia. The aim of this study is to assess the prevalence of asymptomatic hiatal hernia in obese patients in routine upper $\mathrm{Gl}$ endoscopy assessment and correlation with BMI. Methods This was an observational retrospective cohort study conducted at King Fahad Specialist hospital - Buraydah, Qassim, Saudi Arabia. The data were extracted from the medical records and electronic charts of all obese patients who had preoperative upper gastrointestinal endoscopy assessment between January 2017 - December 2019. Data were tabulated in Microsoft Excel and were analyzed using SPSS version 21. Results Among the 690 obese patients, the prevalence of $\mathrm{HH}$ was 103 yielding an overall percentage of $14.9 \%$. Chi-square test revealed that the abdominal pain $(X 2=3.885 ; p=0.049)$, shortness of breath $(X 2=8.057 ; p=0.005)$, vomiting $(X 2=4.302 ; p=0.038)$, nausea $(X 2=4.090 ; p=0.043)$ and other $\mathrm{HH}$ symptoms $(X 2=3.897 ; p=0.048)$ significantly influenced $\mathrm{HH}$ but the $B M I$ level did not $(X 2=2.126 ; p=0.345)$. In multivariate regression model, the use of PPI medication ( $A O R=0.237 ; C l=0.074-0.760 ; p=0.023)$, while vomiting ( $A O R=1.722$; $\mathrm{Cl}=1.025-2.890 ; \mathrm{p}=0.040)$ and nausea $(\mathrm{AOR}=1.698 ; \mathrm{Cl}=1.012-2.849 ; \mathrm{p}=0.045)$ significantly increased the risk of $\mathrm{HH}$. Conclusion Asymptomatic $\mathrm{HH}$ among obese patients is not widely prevalent in our region. The use of PPI medications was found to decrease the symptoms associated with $\mathrm{HH}$ while symptoms such as vomiting and nausea increased the risk of $\mathrm{HH}$. However, there was no evidence found linking BMI to $\mathrm{HH}$ as shown in this study.

\section{Introduction}

Obesity can affect one's health in many ways including hiatal hernia, i.e., dilation in the diaphragmatic opening through which the esophagus passes. This dilation can cause part or the whole stomach to migrate into the thoracic cavity (1). A prospective study included 1224 participants who were sent for upper gastrointestinal endoscopy and found that $65 \%$ of patients with increased waist-to-hip (W/R) ratio present with esophagitis or hiatal hernia (2). Patients with hiatal hernia or esophagitis can show no or few symptoms. It can be found incidentally while investigating digestive disorders using upper gastrointestinal tract endoscopy (3).

Hiatal Hernia is classified as sliding hiatal hernia. This type is the most common type ( $95 \%$ of patients); para-esophageal hiatal hernia is seen when the lower esophageal sphincter remains preserved while the fundus of the stomach herniates through the diaphragm. There is also a mixed type. The fourth type involves the migration of stomach or bowel. The common symptoms of this disease include dysphagia, heartburn, regurgitation, nausea/vomiting, chest pain, or abdominal pain (4). There are multiple risk factors associated with hiatal hernias including age, gender, race, BMI, or any increase in the intraabdominal pressure (1). Hiatal hernia can be detected using multiple studies. However, only two studies can accurately diagnose hiatal hernia including barium swallow and upper endoscopy (4). 
Looking at variations in the incidence and frequency among obese patients and the correlation with asymptomatic hiatal hernia between studies-and considering that the prevalence of asymptomatic hiatal hernia in Al'Qassim province in Saudi Arabia has not been yet established-we conducted a retrospective study on this topic. We then compared the results with other studies conducted inside and outside Saudi Arabia to fully understand the prevalence. The aim of this study was to determine the prevalence of asymptomatic $\mathrm{HH}$ in obese patients in routine upper $\mathrm{Gl}$ endoscopy screening and to assess the relation between $\mathrm{BMI}$ and the presence of hiatal hernia.

\section{Materials And Methods}

An observational retrospective cohort study was conducted at King Fahad Specialist hospital - Buraydah, Qassim, Saudi Arabia. The study was approved by the Institutional Review Board (IRB) of National Bioethics Committee (NCBE) at Qassim province. The data were extracted from the medical records and electronic charts of all obese patients who had upper gastrointestinal endoscopy screening between January 2017 - December 2019. Demographic, clinical, and endoscopic data were collected from electronic health records. All obese patients who had upper gastrointestinal endoscopy screening between January 2017 - December 2019 were included. Patients who had a diagnostic upper GIT endoscopy but with no evidence of hiatus hernia were excluded.

Qualitative data were expressed as frequencies and percentages. Quantitative data were expressed as mean and standard deviation. The relationship between hiatal hernia among the basic demographic characteristics and associated diseases of obese patients was established using a Chi square test. A non-parametric test was used for non-normally distributed variables, and the variables were expressed as the median and interquartile range. A multivariate regression analysis was also conducted to determine the independent significant factor associated with $\mathrm{HH}$ where the adjusted ratio as well as $95 \%$ confidence interval were also reported. A p-value of $<0.05$ was considered statistically significant. All statistical analyses were performed using Statistical Packages for Software Sciences (SPSS) version 21 Armonk, New York, IBM Corporation, USA.

\section{Result}

Table 1: Basic demographic data of obese patients. ${ }^{(n=690)}$ 


\begin{tabular}{ll}
\hline Study Data & N (\%) \\
\hline Age group & $182(26.4 \%)$ \\
- $15-25$ years & \\
- $26-35$ years & \\
- $36-45$ years & $155(22.5 \%)$ \\
- $>55$ years & $119(17.2 \%)$
\end{tabular}

Gender

- Male

296 (42.9\%)

- Female

394 (57.1\%)

Nationality

- Saudi

686 (99.4\%)

- Non-Saudi

04 (0.60\%)

BMI Level

- Severely Obese

$146(21.2 \%)$

- Morbidly Obese

373 (54.1\%)

- Super Obese

171 (24.8\%)

Use of PPI

- Yes

12 (01.7\%)

678 (98.3\%)

- No

The data from a total of 690 obese patients who had upper gastrointestinal screening from January 2017 to December 2019 were analyzed. Table 1 presents the basic demographic characteristics of our patients. The range of patients' age was from 15 to 63 years old (mean: 33.9) with $26-35$ years being the most common age group (33.9\%). Females were slightly more prevalent $(57.1 \%)$ than women $(42.9 \%)$.

Furthermore, nearly all patients were Saudis $(99.4 \%)$. More than half of them (54.1\%) were classified as morbidly obese. In addition, only $1.7 \%$ were using PPI medications.

Figure 1 shows the prevalence of $\mathrm{HH}$ among obese patients. The prevalence of $\mathrm{HH}$ among obese patients was $14.9 \%$ while the majority were negative from $\mathrm{HH}(85.1 \%)$. 
In figure 2, the most commonly known symptom related to $\mathrm{HH}$ was nausea (15.7\%) followed by vomiting and abdominal pain (both $15.5 \%$, each respectively) while shortness of breath was the least frequent complaint $(0.7 \%)$.

Figure 3 presents chronic diseases associated with obese patients. The most frequently cited chronic disease was diabetes (14.3\%) followed by hypothyroidism (9.1\%) and finally hypertension and asthma (both at $7 \%$ each, respectively).

Table 2: Relationship between HH among the basic demographic and associated diseases of obese patients and the symptoms related to $\mathrm{HH} .{ }^{(\mathrm{n}=690)}$ 


\begin{tabular}{|c|c|c|c|c|}
\hline \multirow[t]{3}{*}{ 7actor } & \multicolumn{2}{|c|}{ Hiatal Hernia } & \multirow[t]{3}{*}{$\mathrm{X}^{2}$} & \multirow[t]{3}{*}{$P$-value ${ }^{\S}$} \\
\hline & Present & Absent & & \\
\hline & $\begin{array}{l}\mathrm{N}(\%) \\
(\mathrm{n}=103)\end{array}$ & $\begin{array}{l}N(\%) \\
(n=587)\end{array}$ & & \\
\hline
\end{tabular}

\begin{tabular}{lllll}
\hline tge group & $66(64.1 \%)$ & $350(59.6 \%)$ & 0.726 & 0.394 \\
$-\leq 35$ years & $37(35.9 \%)$ & $237(40.4 \%)$ & \\
$->35$ years & & &
\end{tabular}

jender

- Male

$50(48.5 \%) \quad 246(41.9 \%) \quad 1.575 \quad 0.209$

- Female

53 (51.5\%) 341 (58.1\%)

Jationality

- Saudi

$103(100 \%) \quad 583(99.3 \%) \quad 0.706 \quad 0.401$

- Non-Saudi

$0 \quad 04(0.70 \%)$

3MI Level

- Severe Obese

$24(23.3 \%) \quad 122(20.8 \%) \quad 2.126 \quad 0.345$

- Morbid Obese

$49(47.6 \%) \quad 324(55.2 \%)$

- Super obese

$30(29.1 \%) \quad 141(24.0 \%)$

Jse of PPI

- Yes

$05(04.9 \%) \quad 07(01.2 \%) \quad 6.876 \quad 0.009$ **

- No

$98(95.1 \%) \quad 580(98.8 \%)$

خhronic diseases *

- Asthma

$04(03.9 \%) \quad 44(07.5 \%) \quad 1.766 \quad 0.184$

- DM

$09(08.7 \%) \quad 90(15.3 \%) \quad 3.101 \quad 0.078$

- HTN

$04(03.9 \%) \quad 44(07.5 \%) \quad 1.766 \quad 0.184$

- Hypothyroidism

$07(06.8 \%) \quad 56(09.5 \%) \quad 0.795 \quad 0.373$

jymptoms of Hiatal Hernia *

- Heartburn

$14(13.6 \%) \quad 68(11.6 \%) \quad 0.337 \quad 0.561$

- Difficulty in swallowing

$07(06.8 \%) \quad 21(03.6 \%) \quad 2.332 \quad 0.127$ 
- Chest pain

$$
07(06.8 \%) \quad 21(03.6 \%) \quad 2.332 \quad 0.127
$$

- Abdominal pain

$$
23(22.3 \%) \quad 86(14.7 \%) \quad 3.885 \quad 0.049 * *
$$

- Shortness of breath

$$
03(02.9 \%) \quad 02(0.30 \%) \quad 8.057 \quad 0.005 \text { ** }
$$

- Vomiting

$$
23(22.3 \%) \quad 84(14.3 \%) \quad 4.302 \quad 0.038 \text { ** }
$$

- Nausea

$23(22.3 \%)$

$85(14.5 \%)$

- Others

$02(01.9 \%) \quad 02(0.30 \%) \quad 3.897 \quad 0.048$ **

* Variable with multiple responses.

$\S$ P-value has been calculated using Chi square test.

** Significant at $\mathrm{p}<0.05$ level.

Chi-square tests were conducted in Table 2 to determine the relationship between $\mathrm{HH}$ among the basic demographic data, chronic diseases, and symptoms related to HH. The results show that the use of PPI $(\mathrm{X} 2=6.876 ; \mathrm{p}=0.009)$ and abdominal pain $(\mathrm{X} 2=3.885 ; \mathrm{p}=0.049)$, shortness of breath $(\mathrm{X} 2=8.057 ; \mathrm{p}=0.005)$, vomiting $(\mathrm{X} 2=4.302 ; \mathrm{p}=0.038)$, nausea $(\mathrm{X} 2=4.090 ; \mathrm{p}=0.043)$ and other HH symptoms $(\mathrm{X} 2=3.897 ; \mathrm{p}=0.048)$ have a significant relationship with the presence $\mathrm{HH}$.

Table 3: Multivariate regression analysis to detect the independent significant predictor associated with hiatal hernia. ${ }^{(n=690)}$ 


\begin{tabular}{llll}
\hline actor & AOR & $95 \%$ CI & P-value \\
\hline Jse of PPI & & & \\
- Yes & 0.237 & $0.074-0.760$ & $0.023 * *$ \\
- No & Ref & &
\end{tabular}

łbdominal pain

- Yes

$$
\begin{array}{lll}
1.587 & 0.920-2.739 \quad 0.097
\end{array}
$$

- No Ref

¡hortness of breath

- Yes

$4.987 \quad 0.739-33.664 \quad 0.099$

- No

Ref

Jomiting

- Yes

$1.722 \quad 1.025-2.890 \quad 0.040 * *$

- No

Ref

Jausea

- Yes

$1.698 \quad 1.012-2.849 \quad 0.045 * *$

- No

Ref

ther symptoms

- Yes

$6.666 \quad 0.925-48.049 \quad 0.060$

- No

Ref

AOR - Adjusted Odds Ratio; CI - Confidence Interval.

** Significant at $\mathrm{p}<0.05$ level.

Multivariate regression estimates (Table 3) showed the independent significant factor associated with $\mathrm{HH}$. The risk of having $\mathrm{HH}$ was likely to decrease as much as $80 \%$ for those patients who were using PPI medication $(A O R=0.237 ; \mathrm{Cl}=0.074-0.760 ; \mathrm{p}=0.023)$. Patients with vomiting were nearly two-fold more likely to have $\mathrm{HH}(\mathrm{AOR}=1.722 ; \mathrm{Cl}=1.025$ - 2.890; $\mathrm{p}=0.040)$ while patients with nausea had 1.6-fold higher risk $(A O R=1.698 ; \mathrm{Cl}=1.012-2.849 ; \mathrm{p}=0.045)$.

\section{Discussion}


Hiatus hernia is a stomach disorder that involves herniation of the contents of the abdominal cavity. In United States, reports between 2003 and 2006 indicated that $\mathrm{HH}$ was the primary and secondary cause of hospitalization in 142 of 10,000 inpatients (5). However, the exact prevalence of $\mathrm{HH}$ is difficult to ascertain due to the inherent subjectivity of diagnostic criteria. In this study, we sought to determine the prevalence of asymptomatic $\mathrm{HH}$ among obese patients and evaluate whether it has any link to BMI level. The prevalence of asymptomatic $\mathrm{HH}$ in this study was low (14.9\%). Several papers have documented the prevalence of $\mathrm{HH}$ among obese patients or patients with gastrointestinal problems ranging from $9.3 \%$ to $37 \%(2,6-10)$. Che et al. (6) recorded the highest prevalence of $\mathrm{HH}(37 \%)$ while Hyun et al. (7), recorded a very low prevalence $(9.3 \%)$. The prevalence of $\mathrm{HH}$ in this study was consistent from the paper of Petersen et al. (8) who reported a prevalence of $17 \%$ among patients with gastroesophageal reflux symptoms.

Age and obesity are the most commonly known risk factors of $\mathrm{HH}$ (10-12). Compared to people with normal body weight, overweight or obese people had a progressive increase in intra-abdominal pressure, which leads to herniation (13). Wilson and Hirschowitz found that the presence of $\mathrm{HH}$ was significantly associated with excessive body weight and the probability of $\mathrm{HH}$ increased with each level of BMI (14). This has been validated in a meta-analysis conducted by Menon and Trudgill (15) who observed that the odds ratio for $\mathrm{HH}$ in people with a BMI greater than 25 was 1.93 (95\% confidence interval 1.10 to 3.39) with risk increasing as the BMI increased. However, in our study, we failed to prove the correlation between $\mathrm{BMI}$ and $\mathrm{HH}(\mathrm{X} 2=2.126 ; \mathrm{p}=0.345)$; age was not a significant predictor in contrast to previous results.

Further analysis univariate determined that the use of PPI medication as well as abdominal pain, shortness of breath, vomiting, nausea, and other symptoms of $\mathrm{HH}$ significantly influenced $\mathrm{HH}$. However, after conducting multivariate regression estimates, we found that the use of PPI medication significantly decreased the presence of $\mathrm{HH}$ while vomiting and nausea significantly increased the risk of $\mathrm{HH}$. This indicates that the use of PPI was likely a protective factor of $\mathrm{HH}$ whereas vomiting and nausea are the significant risk factors associated with $\mathrm{HH}$. Other reports discussed gender and $\mathrm{HH}$ and found that males were more frequently diagnosed with $\mathrm{HH}$ than females $(6,15)$. In our paper, the relationship between gender did not differ significantly with $\mathrm{HH}$ in contrast to previous results.

Moreover, this study suggests that no specific symptoms are attributed to $\mathrm{HH}$. Symptoms related to gastroesophageal reflux including heartburn, regurgitation, or dysphagia were linked to $\mathrm{HH}$ due to the occurrence of hernia (16). In our study, the most common symptoms related to $\mathrm{HH}$ were nausea (15.7\%) followed by vomiting and abdominal pain (each $15.5 \%$ ); shortness of breath was the least common symptom $(0.7 \%)$ which is not similar to previous findings.

\section{Conclusion}

Asymptomatic $\mathrm{HH}$ among obese patients is not common in Saudi Arabia. The use of PPI medications is a protective factor of $\mathrm{HH}$ while symptoms such as vomiting and nausea increased the risk of $\mathrm{HH}$. On the 
other hand, there was no evidence linking $\mathrm{BMI}$ to $\mathrm{HH}$ as shown in this study. More research is needed the validate the prevalence of asymptomatic $\mathrm{HH}$ associated with obese patients in our region.

\section{List Of Abbreviations}

$\mathrm{HH}$, Hiatus Hernia

W/R, waist-to-hip

PPI, Proton-pump inhibitors

\section{Declarations}

1. Che F, Nguyen B, Cohen A, Nguyen NT. Prevalence of hiatal hernia in the morbidly obese. Surg Obes Relat Dis. 2013;9(6):920-4.

2. Wilson LJ, Ma W, Hirschowitz BI. Association of obesity with hiatal hernia and esophagitis. The American Journal of Gastroenterology. 1999;94(10):2840-4.

3. Verset D, Houben J-J, Gay F, Elcheroth J, Bourgeois V, Van Gossum A. The place of upper gastrointestinal tract endoscopy before and after vertical banded gastroplasty for morbid obesity. Digestive Diseases and Sciences. 1997;42(11):2333-7.

4. Kahrilas PJ. Hiatus hernia. In: Post TW, ed. UpToDate. Waltham, MA: UpToDate. Last updated July 25, 2016. Accessed January 13, 2017.

5. Shah-Khan SM, Chaudhary F, Abdelqader A, Kupec JT, Szoka N. Detection of hiatal hernias: comparison of high-resolution manometry and physician reported in an obese-predominant population. BMJ Open Gastroenterol. 2019;6(1):e000300.

6. Thukkani N, Sonnenberg A. The influence of environmental risk factors in hospitalization for gastrooesophageal reflux disease-related diagnoses in the United States. Aliment Pharmacol Ther 2010;31:852-61.

7. Santonicola A, Angrisani L, Vitiello A, Tolone S, Trudgill NJ, Ciacci C, lovino P. Hiatal hernia diagnosis prospectively assessed in obese patients before bariatric surgery: accuracy of high-resolution manometry taking intraoperative diagnosis as reference standard. Surgical endoscopy. 2020 Mar;34(3):1150-6.

8. Dyer, N. and R. Pridie (1968). "Incidence of hiatus hernia in asymptomatic subjects." Gut 9(6): 696.

9. Hyun JJ, Kim JH, Yeon JE, Park JJ, Kim JS, Byun KS, Bak YT. Short segment hiatal hernia: is it a clinically significant entity? Journal of Neurogastroenterology and Motility. 2010 Jan;16(1):35.

10. Petersen H, Johannessen T, Sandvik AK, Kleveland PM, Brenna E, Waldum H, Dybdahl JD. Relationship between endoscopic hiatus hernia and gastroesophageal reflux symptoms. Scandinavian Journal of Gastroenterology. 1991 Jan 1;26(9):921-6. 
11. Sgouros SN, Mpakos D, Rodias M, Vassiliades K, Karakoidas C, Andrikopoulos E, Stefanidis G, Mantides A. Prevalence and axial length of hiatus hernia in patients, with nonerosive reflux disease: a prospective study. Journal of Clinical Gastroenterology. 2007 Oct 1;41(9):814-8.

12. Sakaguchi M, Oka H, Hashimoto T, Asakuma Y, Takao M, Gon G, Yamamoto M, Tsuji Y, Yamamoto N, Shimada M, Lee K. Obesity as a risk factor for GERD in Japan. Journal of Gastroenterology. 2008 Jan;43(1):57-62.

13. Stene-Larsen G, Weberg R, Froyshov Larsen I, Bjortuft O, Hoel B, Berstad A. Relationship of overweight to hiatus hernia and reflux oesophagitis. Scand J Gastroenterol 1988;23:427-32.

14. Pandolfino JE, El-Serag HB, Zhang Q, Shah N, Ghosh SK, Kahrilas PJ. Obesity: a challenge to esophagogastric junction integrity. Gastroenterology 2006;130:639-49.

15. Menon S, Trudgill N. Risk factors in the aetiology of hiatus hernia: a metaanalysis. Eur $\mathrm{J}$ Gastroenterol Hepatol 2011;23:133-8.

16. Pandolfino JE, Kwiatek MA, Ho K, Scherer JR, Kahrilas PJ. Unique features of esophagogastric junction pressure topography in hiatus hernia patients with dysphagia. Surgery 2010;147:57-64.

\section{References}

1. Che F, Nguyen B, Cohen A, Nguyen NT. Prevalence of hiatal hernia in the morbidly obese. Surg Obes Relat Dis. 2013;9(6):920-4.

2. Wilson LJ, Ma W, Hirschowitz BI. Association of obesity with hiatal hernia and esophagitis. The American Journal of Gastroenterology. 1999;94(10):2840-4.

3. Verset D, Houben J-J, Gay F, Elcheroth J, Bourgeois V, Van Gossum A. The place of upper gastrointestinal tract endoscopy before and after vertical banded gastroplasty for morbid obesity. Dig Dis Sci. 1997;42(11):2333-7.

4. Kahrilas PJ. Hiatus hernia. In: Post TW, ed. UpToDate. Waltham, MA: UpToDate. Last updated July 25, 2016. Accessed January 13, 2017.

5. Shah-Khan SM, Chaudhary F, Abdelqader A, Kupec JT, Szoka N. Detection of hiatal hernias: comparison of high-resolution manometry and physician reported in an obese-predominant population. BMJ Open Gastroenterol. 2019;6(1):e000300.

6. Thukkani N, Sonnenberg A. The influence of environmental risk factors in hospitalization for gastrooesophageal reflux disease-related diagnoses in the United States. Aliment Pharmacol Ther. 2010;31:852-61.

7. Santonicola A, Angrisani L, Vitiello A, Tolone S, Trudgill NJ, Ciacci C, lovino P. Hiatal hernia diagnosis prospectively assessed in obese patients before bariatric surgery: accuracy of high-resolution manometry taking intraoperative diagnosis as reference standard. Surgical endoscopy. 2020 Mar;34(3):1150-6.

8. Dyer N, Pridie R. "Incidence of hiatus hernia in asymptomatic subjects" Gut. 1968;9(6):696. 
9. Hyun JJ, Kim JH, Yeon JE, Park JJ, Kim JS, Byun KS, Bak YT. Short segment hiatal hernia: is it a clinically significant entity? Journal of Neurogastroenterology Motility. 2010 Jan;16(1):35.

10. Petersen H, Johannessen T, Sandvik AK, Kleveland PM, Brenna E, Waldum H, Dybdahl JD. Relationship between endoscopic hiatus hernia and gastroesophageal reflux symptoms. Scandinavian Journal of Gastroenterology. 1991 Jan 1;26(9):921-6.

11. Sgouros SN, Mpakos D, Rodias M, Vassiliades K, Karakoidas C, Andrikopoulos E, Stefanidis G, Mantides A. Prevalence and axial length of hiatus hernia in patients, with nonerosive reflux disease: a prospective study. Journal of Clinical Gastroenterology. 2007 Oct 1;41(9):814-8.

12. Sakaguchi M, Oka H, Hashimoto T, Asakuma Y, Takao M, Gon G, Yamamoto M, Tsuji Y, Yamamoto N, Shimada M, Lee K. Obesity as a risk factor for GERD in Japan. Journal of Gastroenterology. 2008 Jan;43(1):57-62.

13. Stene-Larsen G, Weberg R, Froyshov Larsen I, Bjortuft O, Hoel B, Berstad A. Relationship of overweight to hiatus hernia and reflux oesophagitis. Scand J Gastroenterol. 1988;23:427-32.

14. Pandolfino JE, El-Serag HB, Zhang Q, Shah N, Ghosh SK, Kahrilas PJ. Obesity: a challenge to esophagogastric junction integrity. Gastroenterology. 2006;130:639-49.

15. Menon S, Trudgill N. Risk factors in the aetiology of hiatus hernia: a metaanalysis. Eur J Gastroenterol Hepatol. 2011;23:133-8.

16. Pandolfino JE, Kwiatek MA, Ho K, Scherer JR, Kahrilas PJ. Unique features of esophagogastric junction pressure topography in hiatus hernia patients with dysphagia. Surgery. 2010;147:57-64.

\section{Figures}

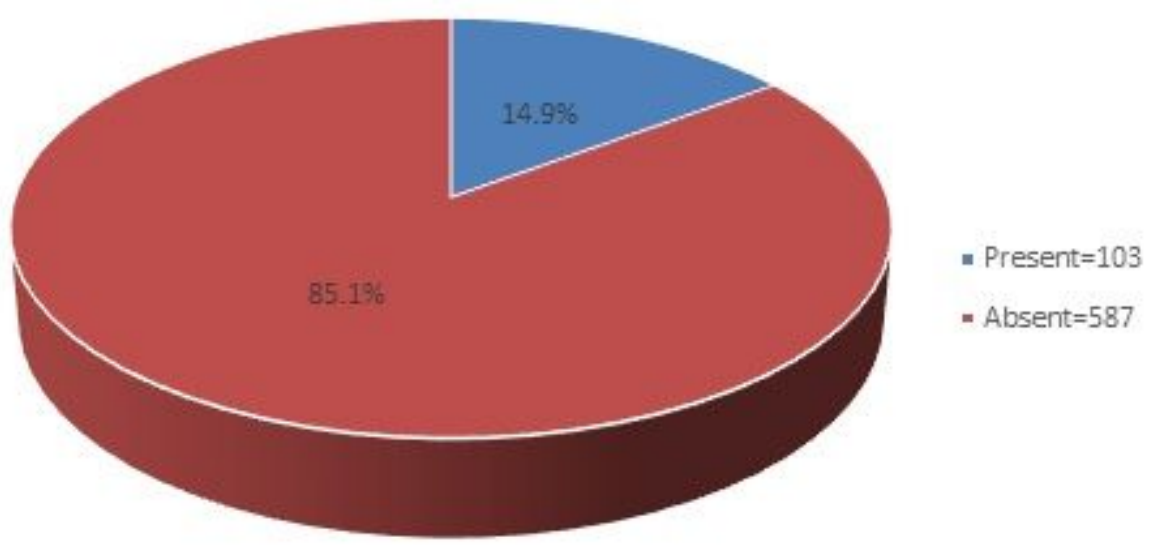

\section{Figure 1}

Prevalence of $\mathrm{HH}$ among obese patients. 


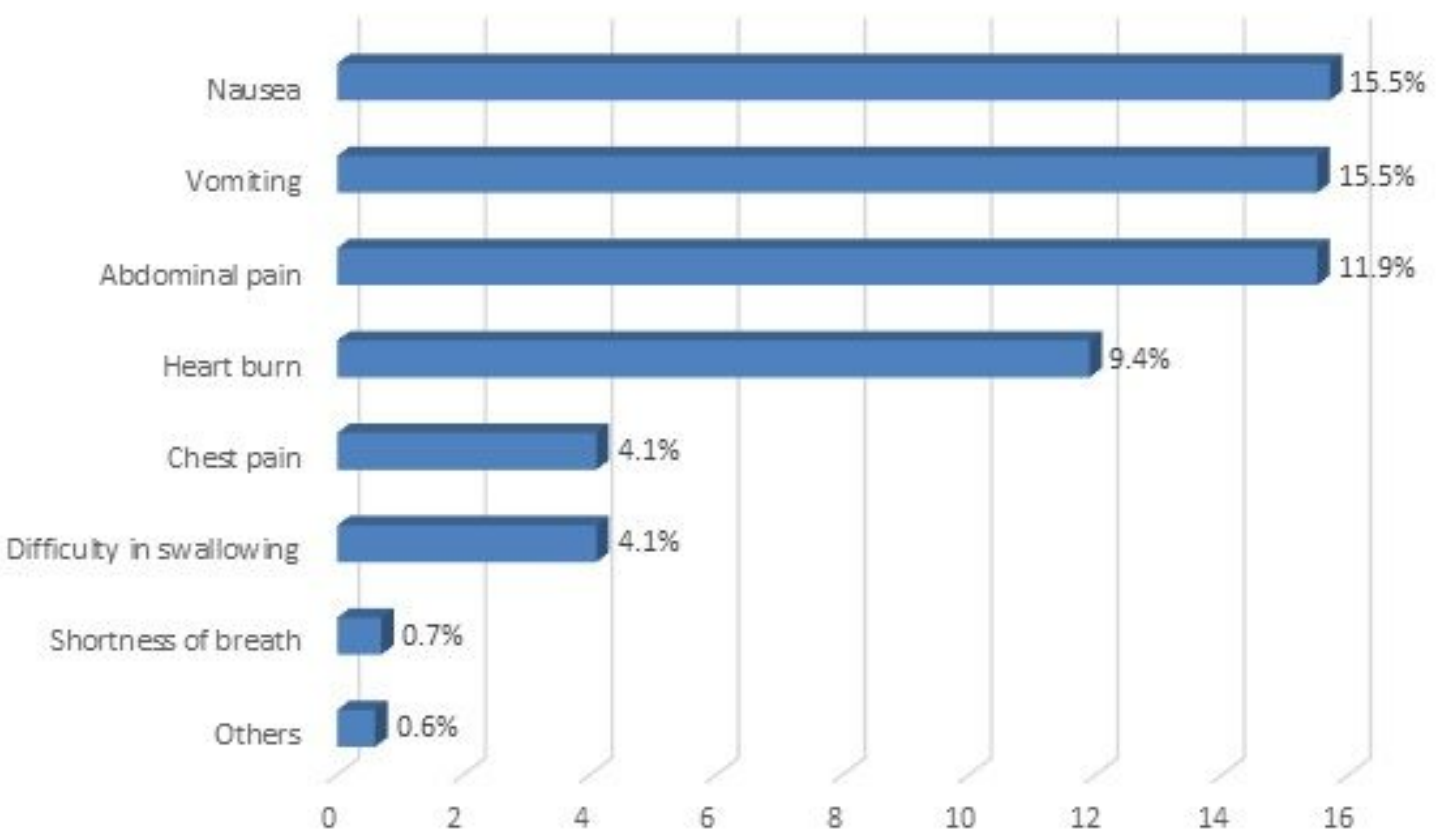

Figure 2

Symptoms related to hiatal hernia.

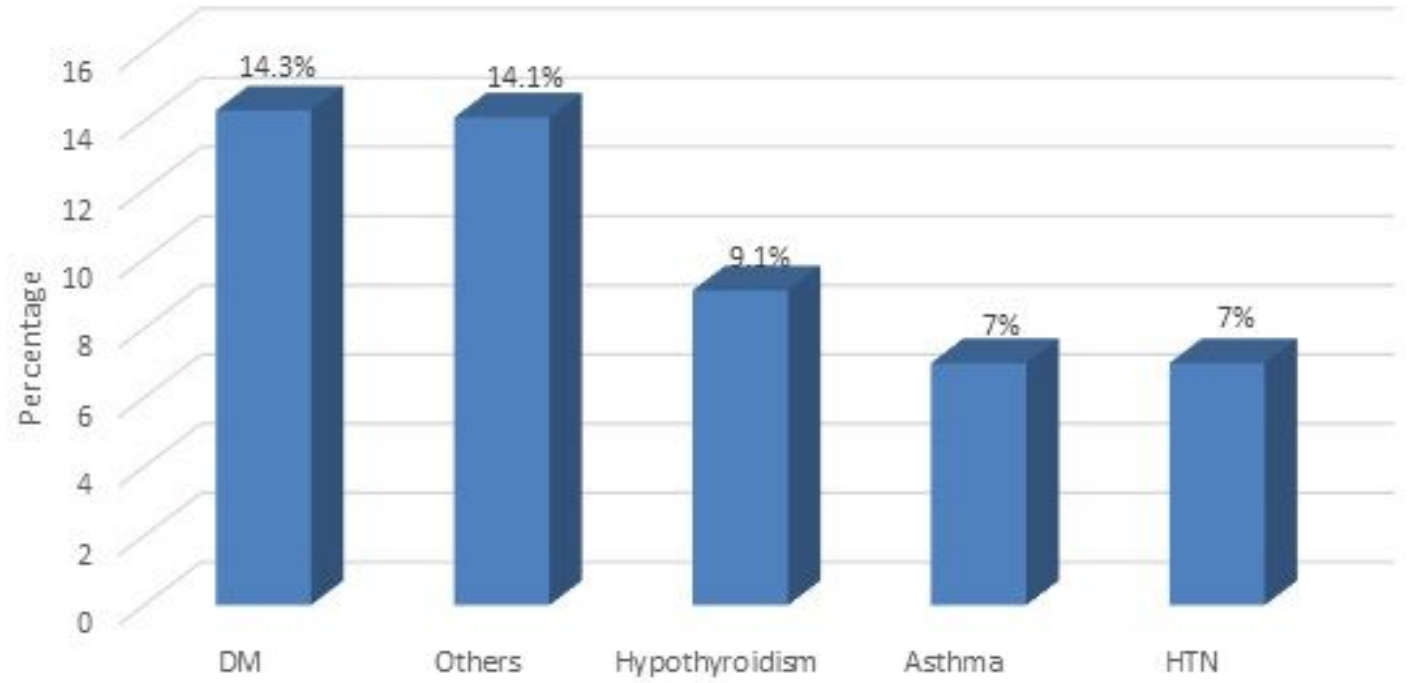

Figure 3

Chronic diseases of the obese patients. 